\title{
The neuromuscular junction: aging at the crossroad between nerves and muscle
}

\author{
Marta Gonzalez-Freire ${ }^{1,2}$, Rafael de Cabo ${ }^{1}$, Stephanie A. Studenski ${ }^{1,2}$ and Luigi Ferrucci ${ }^{1,2}$ \\ ${ }^{1}$ Translational Gerontology Branch, National Institute on Aging, Intramural Research Program, National Institutes of Health, Baltimore, MD, USA \\ ${ }^{2}$ Longitudinal Studies Section, Baltimore Longitudinal Study of Aging, National Institute on Aging, National Institutes of Health, Baltimore, MD, USA
}

\section{Edited by:}

Brian C. Clark, Ohio University, USA

\section{Reviewed by:}

David J. Clark, Malcom Randall VA

Medical Center, USA

David W. Russ, Ohio University, USA

Michael R. Deschenes, College of

William and Mary, USA

${ }^{*}$ Correspondence:

Marta Gonzalez-Freire, Translational

Gerontology Branch, National

Institute on Aging, BRC Room

09C506, 251 Bayview Blvd Baltimore,

MD 21224, USA

e-mail: marta.gonzalezfreire@nih.gov
Aging is associated with a progressive loss of muscle mass and strength and a decline in neurophysiological functions. Age-related neuromuscular junction (NMJ) plays a key role in musculoskeletal impairment that occurs with aging. However, whether changes in the NMJ precede or follow the decline of muscle mass and strength remains unresolved. Many factors such as mitochondrial dysfunction, oxidative stress, inflammation, changes in the innervation of muscle fibers, and mechanical properties of the motor units probably perform an important role in NMJ degeneration and muscle mass and strength decline in late life. This review addresses the primary events that might lead to NMJ dysfunction with aging, including studies on biomarkers, signaling pathways, and animal models. Interventions such as caloric restriction and exercise may positively affect the NMJ through this mechanism and attenuate the age-related progressive impairment in motor function.

Keywords: aging, denervation, motor unit, neuromuscular junction, sarcopenia

\section{INTRODUCTION}

Autopsy studies in persons who died of acute trauma while relatively healthy have shown that aging is associated with a gradual loss of motor neurons (Valdez et al., 2010; Rowan et al., 2012). The mechanism that leads to neuronal loss with aging is still unclear and may involve both impaired trophic signaling from the central nervous system (CNS), local degeneration, and feedback from dysfunctional muscle. Indeed, individuals over 65 years of age exhibit reduced activity in motor brain areas, increased oxidative stress in motor neurons and impaired energetic metabolism in muscle fibers (Deschenes et al., 2010; Ferrucci et al., 2012; Reid et al., 2012, 2014; Manini et al., 2013). However, there is evidence that this decrease in muscle energetic metabolism is not solely affected by aging but also by the levels of physical activity, suggesting that energetic changes are more likely to be a function of activity, and not time (Tevald et al., 2010; Russ and Lanza, 2011).

Regardless of the cause, when a motor neuron is lost, fibers previously innervated by that neuron, globally defined as a motor unit, are no longer controlled by the nervous system and fail to contribute to the force generated during a volitional muscle contraction. In the attempt to counteract the functional consequence of this process, denervated orphan fibers express proteins and produce chemotactic signals that stimulate the sprouting of new dendrites from residual motor neurons. This process leads re-innervation by the expansion of pre-existing motor units and is aimed at returning to function previously denervated muscle fibers. This dynamic denervation-re-innervation cycle successfully compensates for neuronal loss, with little decline in global strength and only slightly reduced control. However, there is evidence that this compensatory mechanism starts failing with aging. Some denervated fibers are not successfully re-innervated, become apoptotic, and are not replaced by new fibers. It is hypothesized that this phenomenon contributes to a progressive decline in muscle mass and strength with aging.

The reason for a progressive impairment of the re-innervation process with aging is unknown, but some lines of evidence point to changes that occur with aging in the neuromuscular junction (NMJ), which is the synaptic interface between a branch of a motor neuron and muscle cells. The NMJ is composed of three elements: pre-synaptic (motor nerve terminal), intrasynaptic (synaptic basal lamina), and post-synaptic part (muscle fiber and muscle membrane) (Punga and Ruegg, 2012). When an action potential reaches the pre-synaptic element, voltage-dependent calcium channels open allowing calcium to enter the neuron and trigger the delivery of acetylcholine (ACh) in the synaptic cleft. Acetylcholine triggers nicotin acetylcholine receptors (nAChR) located in the post-synaptic membrane to produce an action potential, which in turn, activates voltage-gated dihydropyridine receptors (DHPRs) located in the sarcolemma and by induction, ryanodine receptors (RyRs). Of note, the post-synaptic membrane presents folds that expand its area. Calcium released from the sarcoplasmic reticulum through the RyRs binds to troponin $\mathrm{C}$ and allows cross-bridge cycling and force production (Figure 1).

Over the last decade, age-associated degeneration of the NMJ has been reported. It has been proposed that such changes may be causally related to the decline in muscle mass and function that occurs in most aging individuals. However, whether changes in the NMJ precede or follow the decline of muscle mass and strength remains unresolved. Understanding whether the primary event in the pathway to sarcopenia is muscle denervation, NMJ fragmentation or muscle fiber degeneration is important because the identification of the source of the primary event influences strategies to delay the onset of age-related muscle dysfunction. In this report, we review our current understanding of the events that lead to NMJ dysfunction with aging, including studies on biomarkers, 


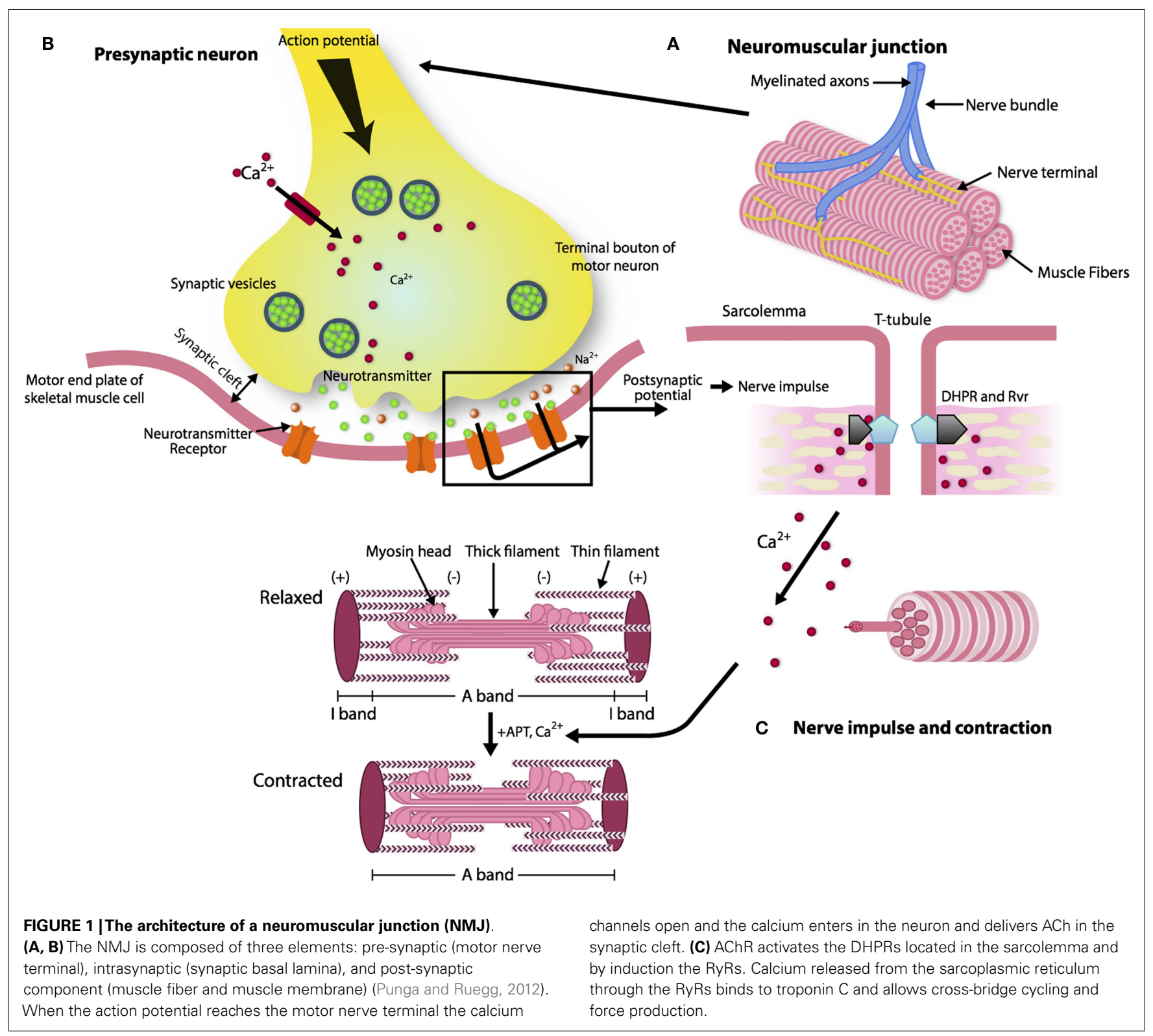

signaling pathways, and animal models. We propose that interventions aimed at preventing the deterioration of the NMJ should be aimed at reversing the mechanisms that lead to NMJ degeneration with aging. It is important to underline that our comprehension of the global mechanism that lead to NJM impairment with aging is still patchy. Some of the elements emerging in the literature will be described and their relationship with aging explored. However, it is worth noticing that how these different parts participate and interact within a unique global mechanism and cause NMJ dysfunction with aging is not understood.

\section{THE AGED NEUROMUSCULAR JUNCTION CHANGES THAT OCCUR WITH AGING IN THE NMJ}

The structure of the NMJ varies depending on the muscle fiber innervated and potentially on the level of muscle activity (Smith and Rosenheimer, 1982; Rosenheimer and Smith, 1985;
Arrowsmith, 2007). There is strong evidence that changes in endplate morphology and NMJ remodeling occur with aging and precede loss of fast motor units. Morphologically, both the nerve terminal area and the number of post-synaptic folds are reduced leading to a functional impairment in the post-synaptic response of the NMJ (i.e., motor nerve conduction velocity becomes slower and the amplitude of compound muscle action potential (CMAP) decreases) (Kurokawa et al., 1999). Mitochondria in the plaque region are numerically reduced and tend to show signs of degeneration. In particular, some authors have described dramatic alterations in mitochondrial morphology in axon terminals, including cristae disruption, swelling, and formation of megamitochondria due to multiple fusions between adjacent mitochondria (Garcia et al., 2013). Studies of pre-synaptic plaque changes with aging have found high levels of oxidative damage, decreased number of synaptic vesicles, and lower quantities of neurotransmitter 
released during depolarization (Figure 2). These changes have been correlated with denervation of muscle fibers and muscle atrophy occurring in a fiber dependent manner (Banker et al., 1983; Jang and Van Remmen, 2011; Rowan et al., 2012). Hypothesized mechanisms include (1) progressively reduced capacity of motor neurons to re-innervate muscle fibers that are denervated or regenerating; (2) impaired excitation-contraction coupling; and (3) age-associated decline in satellite cell proliferation (Clark and Fielding, 2012; Rosso et al., 2013) (Figure 3). In particular, Clark and Fielding (2012) suggest that the NMJ activation of muscle agonists is impaired in some older adults in whom weakness is more prominent than reduced muscle mass.

As mentioned previously, some studies (Li et al., 2011) suggest that in mice, NMJ changes follow degeneration and regeneration of individual muscle fibers, while others suggest that muscle denervation might be a consequence of high energetic demand in skeletal muscle fibers, as found in human mutant SOD1 (mSOD1) mice who develop amyotrophy and muscle denervation (Dupuis et al., 2004, 2009, 2011).

\section{Mitochondrial dysfunction and oxidative stress in NMJ dysfunction}

Mitochondria play a critical role in regulating energy production, metabolism, signal transduction, and apoptosis and are also the primary source of oxygen free radicals generated by the dislocation of electrons traveling across the respiratory chain (Peterson et al., 2012). The numerous mitochondria in the axon not only provide energy but also buffer the large calcium ion loads which are essential for excite-contraction coupling (Barrett et al., 2011). Decline in number and function of mitochondria as well as frequent modification of their morphological structure with aging has been described in many tissues, including skeletal muscle. Dysfunctional mitochondria are often found with aging, characterized by increased levels of oxidation and nitrosylation products and decreased enzymatic activity. It has been hypothesized that the diffusion of mitochondrial nitric oxide $(\mathrm{NO})$ and hydrogen peroxide $\left(\mathrm{H}_{2} \mathrm{O}_{2}\right)$ to the cytosol is decreased in the aged brain and may impair mitochondrial biogenesis (Navarro and Boveris, 2009). Since neurons and muscle fibers are highly metabolically active, it is rational to hypothesize that they are affected by even minor mitochondrial dysfunction (Li et al., 2013; Baines et al., 2014). Indeed, it has been recently shown in sarcopenic rats with NMJ disruption that the expression of genes implicated in mitochondrial energy metabolism is down regulated (Ibebunjo et al., 2013). However, the role of oxidative stress in peripheral nervous system aging and pathology remains poorly understood (Lin and Beal, 2006; Garcia et al., 2013). Reduced ATP production and impaired calcium buffering in the subsarcolemmal mitochondria located near the NMJ may impair both neurotransmission and vesicular recycling (Deschenes, 2011).

\section{Changes in the innervation of muscle fibers and motor units}

Neuron loss (cell death) that occurs with aging is progressive and, as far as we know, irreversible. Loss of motor units in young adults results in re-innervation of denervated fibers by sprouting from other motor neurons and in death of fibers that are not successfully re-innervated. The details of this process have been studied mostly in animal models. Chai et al. (2011) have shown that in mice, while the size and number of alpha motor neurons in the

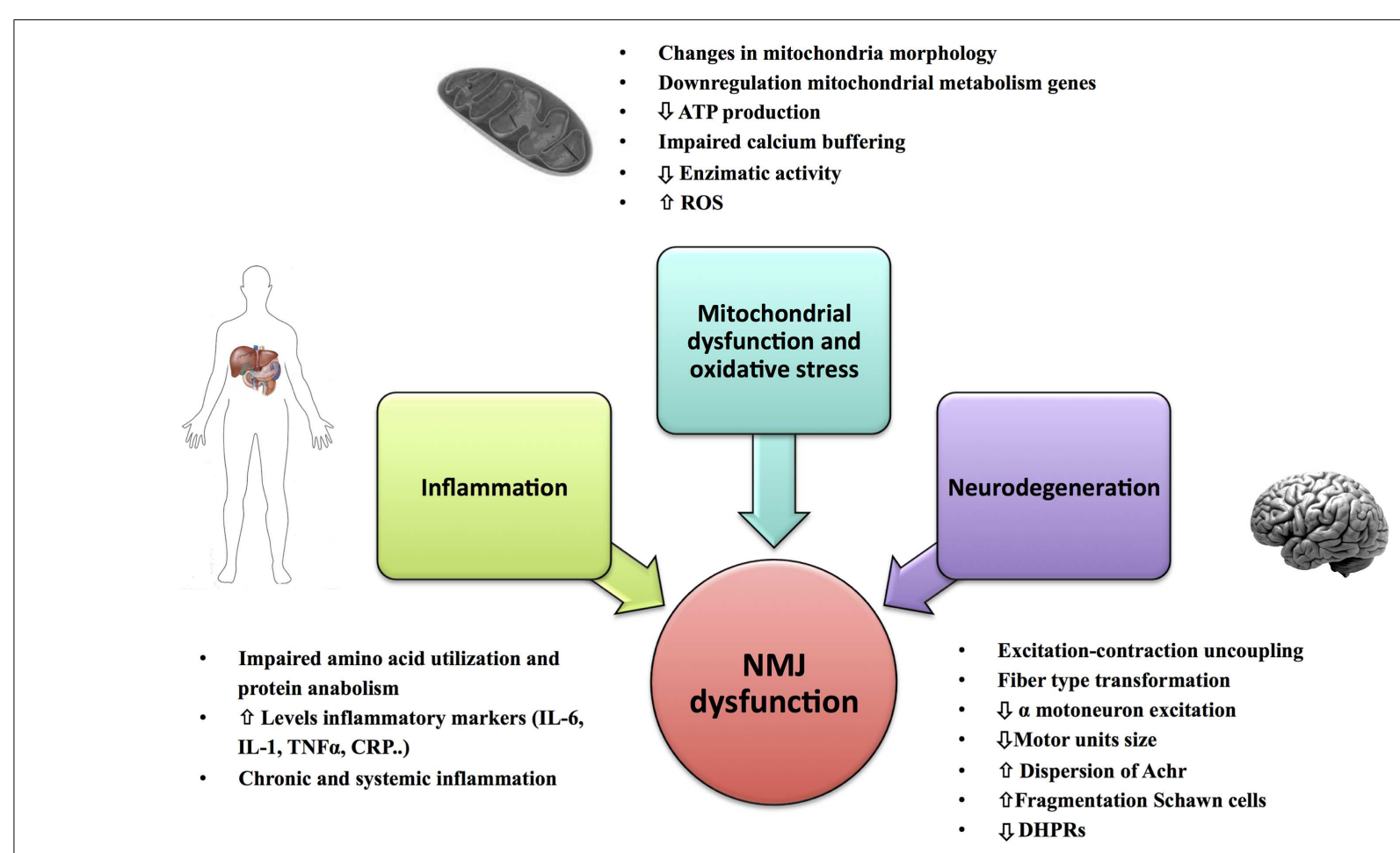

FIGURE 2 | Primary causes of NMJ dysfunction during aging. Factors such as mitochondrial dysfunction, oxidative stress, inflammation, and changes in the innervation of muscle fiber and mechanical properties of the motor units could play an important role in the NMJ degeneration and development of sarcopenia. 


\section{Changes in the Neuromuscular Junction with Aging}

\section{STRUCTURAL CHANGES}

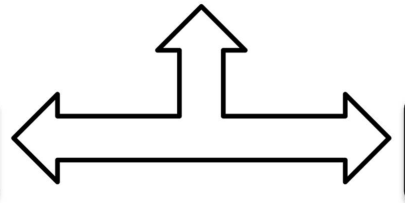

FUNCTIONAL CHANGES

(Mechanical properties)
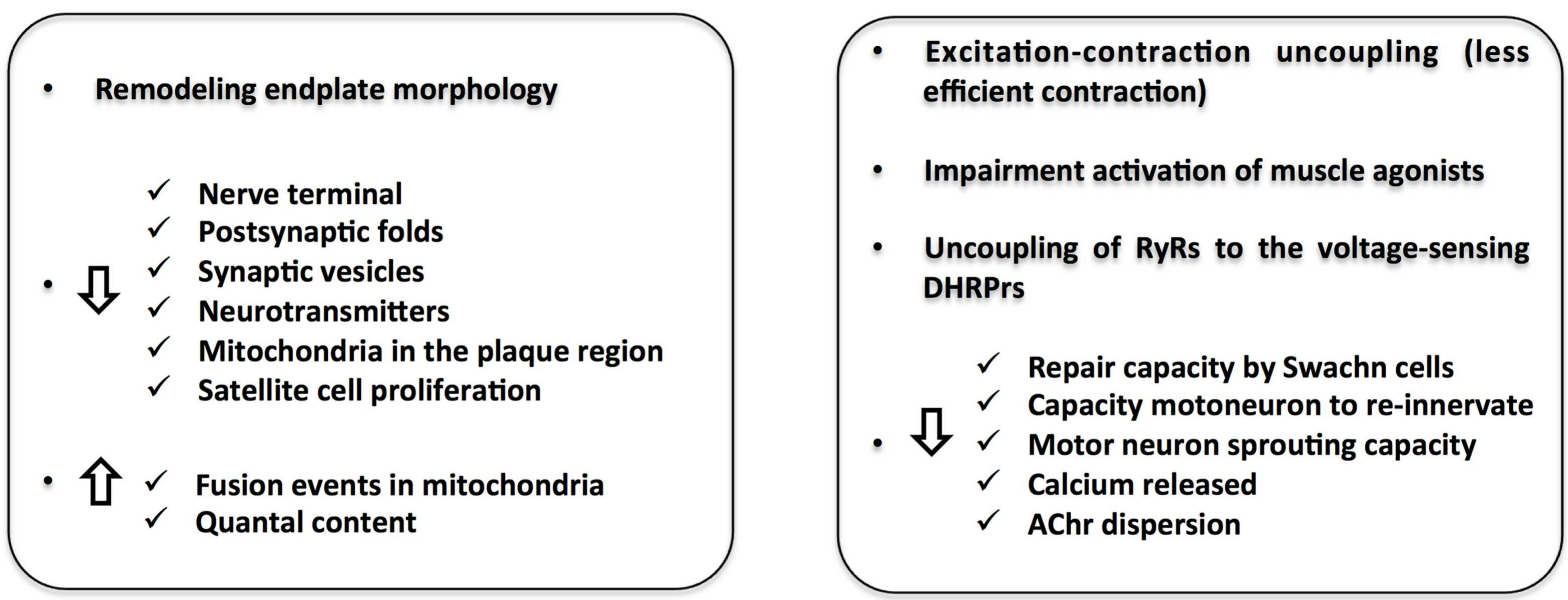

FIGURE 3 | Changes in the neuromuscular junction with aging. Structural changes together with functional alterations result in a NMJ impairment during aging. The excitation-contraction uncoupling leads to a loss of communication between the nervous and muscular system, causing a decline in skeletal muscle strength and muscle mass.

spinal cord do not change until very late in life, profound earlier change is observed at the NMJ. In very late life, motor neurons show impaired capacity to sprout and re-innervate denervated fibers, and as a consequence, larger motor units become smaller, and more fatigable and there is a considerable atrophy of muscle fibers (Luff, 1998; Roubenoff, 2000; Glass and Roubenoff, 2010). Macroscopic age-associated muscle atrophy is due to a combination of individual fiber atrophy and a decrease in the total number of type II fibers (fast and glycolytic muscle fibers) (Lexell, 1995, 1997; Andersen, 2003; Suetta et al., 2012). These alterations in morphologic remodeling in the aged NMJ result in more dispersed AChR, with greater spatial uncoupling between ACh vesicle clusters and receptor clusters. These events together induce physiological adaptations (i.e., changes of a quantal level) in the aged NMJ that have been extensively reviewed by Deschenes (2011).

According to current views, Schwann cells (cells that myelinate axons) play an critical role in synaptic repair following denervation, through their ability to direct axonal regrowth, remyelinate, and allow functional recovery by secreting trophic and growth factors (Rangaraju et al., 2009; Rangaraju and Notterpek, 2011; Kim et al., 2013). Impairment in these cells, such as increased fragmentation, damage, or denervation may contribute to ineffective re-innervation and neuromuscular dysfunction in aging (Verge et al., 1996; Kawabuchi et al., 2001, 2011; Gordon et al., 2009).

Changes that occur at the NMJ with aging are paralleled by a progressive uncoupling of the excitation-contraction in the skeletal muscle (Delbono et al., 1995, 1997; Delbono, 2003). It has been hypothesized that age-related muscle uncoupling is due to a mismatch between DHPR and RyR. In particular RyR would be more numerous than DHPR. This uncoupling reduces calcium release after an action potential, resulting in less efficient contraction (Wang et al., 2004; Shear and Martyn, 2009). It has been shown that insulin-like growth factor-I (IGF-1) could prevent the age-related decline in the number of DHPRs, therefore preventing the changes in nerve terminal and NMJ (Delbono, 2000, 2003; Zheng et al., 2002). These findings suggest that overexpression of IGF-1 may have a role in preventing muscle strength decline with aging.

\section{Inflammation in aging (inflammaging)}

Aging is characterized by high circulating levels of inflammatory markers such as interleukin 6 (IL-6), interleukin 1 (IL-1), tumor necrosis factor alpha (TNF-alpha), and C-reactive protein (CRP) in blood and tissues, often without a clear cause. This chronic low-grade inflammation in older persons has been defined by 
Franceschi et al. (2007) as “inflammaging.” Epidemiological studies have consistently demonstrated that "inflammaging" is a risk factor for accelerated decline of muscle mass and strength with aging, and that these changes in muscle performance may be a critical mediating step in the causal pathway between "inflammaging" and mobility disability (Ferrucci et al., 1999, 2005). In addition, medical conditions characterized by chronic overt inflammation often cause muscle wasting and weakness (Saini et al., 2007, 2009; Degens, 2010; Ferrucci et al., 2013). The mild pro-inflammatory state of aging may affect muscle performance and maintenance in many ways. For example, Schwann cell senescence has been associated with overexpression of IL-6, suggesting a role of inflammation in the age-related alterations in axonal regeneration (Saheb-AlZamani et al., 2013). Chronic inflammation down regulates the production of IGF-1 and blunts its biological activity. Inflammation is associated with impaired amino acid (Aa) utilization and protein anabolism, especially in critical periods such as after a meal or after a bout of exercise.

\section{BIOMARKERS OF NMJ IN AGING AND SIGNALING PATHWAYS}

The direct study of the NMJ in human beings presents challenges that are almost insurmountable. The NMJ is seldom detected in muscle needle biopsies and requires open surgery biopsies that are only done for diagnostic purposes. Newly emerging neurophysiological techniques may be used in the future to study the NMJ but they are still at an early stage of development. One of the most promising areas of investigation and perhaps the one with the strongest translational potential is the study of circulating biomarkers, such as neurotrophic factors, muscle anabolic hormones, and growth factors that are known to have a role in NMJ dysfunction. Although most of the biomarkers addressed in this section are known to change with aging, whether they modulate the causal pathway from aging to NMJ impairment with aging is not fully established. Nevertheless, correlational studies may provide knowledge that in the future may help reconstructing a general model of the mechanism leading to NMJ degeneration with aging.

\section{NEUROTROPHIC FACTORS}

Neurotrophins are a family of proteins implicated in neural development, maintenance, and maturation that also play a role in neurotransmission. Changes in production and response to neurotrophins with aging may contribute to reduced axonal regeneration, and dysfunction at multiple levels, including motor axons, post-synaptic membrane, and Schwann cells. One of the most studied neurotrophic factors is brain-derived neurotrophic factor (BDNF), which plays a critical role in neural plasticity and facilitates synaptic function by increasing pre-synaptic depolarization at the NMJ (Seeburger and Springer, 1993; Springer et al., 1995; Huang and Reichardt, 2001; Lipsky and Marini, 2007; Jiang et al., 2008; Gomez-Pinilla, 2011) and maintaining AChR clustering in the NMJ (Gomez-Pinilla et al., 2002; Peng et al., 2003). Interestingly, there is some initial evidence that production of glia cell-derived neurotrophic factor (GDNF) declines with aging (Li et al., 1995). Denervation leads to an up regulation of GDNF in rat and human skeletal muscle (Lie and Weis, 1998). Consistently, in vitro studies have found that GDNF is a potent trophic factor for motor neuron survival and a potent regulator of pre- and postsynaptic plasticity (Lin et al., 1993; Nguyen et al., 1998). Moreover, GDNF protein content in aged rat skeletal muscle might be controlled by stretching the muscle and the membrane depolarization of AChR acts to decrease GDNF protein content (McCullough et al., 2011).

There is evidence that short-term exercise increases levels of GDNF in the skeletal muscle and spinal cord of young and old rats (McCullough et al., 2013). Gyorkos et al. (2014) found increased GDNF protein levels at the end plate in the soleus and extensor digitorum longus muscles following training, supporting the idea that GDNF is activity dependent. Different models of exercise type and intensity could have varying effects on GDNF protein content in slow- and fast-twitch muscle fibers. The authors concluded that GDNF may play a role in remodeling of the NMJ in slow and fast-twitch muscle fibers.

\section{INSULIN-LIKE GROWTH FACTOR 1}

Insulin-like growth factor 1 is a pleiotropic growth factor with many functions, including a neutrotrophic effect, promotion of motor neuron survival, maintenance of muscle mass and strength, and protection from oxidative stress (Yuan et al., 2000; Maggio et al., 2006, 2013; Apel et al., 2010). Many studies have found that circulating IGF-1 declines with aging and such decline may contribute to NMJ degeneration and motor unit denervation (Delbono, 2003; Messi and Delbono, 2003). In accordance with this hypothesis, in mouse models, the overexpression of musclespecific IGF-1 reverses sarcopenia (Musaro et al., 2001), prevents the age-dependent decrease in type IIB and increase in type IIA fibers (Messi and Delbono, 2003), and also leads to improved nerve regeneration by acting on axons, Schwann cells, and the NMJ. Systemic administration of IGF-1 decreased motor neuron cell death and promoted muscle re-innervation after injury in young animals, suggesting that the decline in IGF-1 with aging may impair the ability of aging animals to repair and maintain the integrity of NMJ (Vergani et al., 1998). IGF-1 sensitivity may not decrease with age, so that IGF-1 could promote regeneration after nerve injury even in older individuals. Overexpression of muscle-specific IGF1 in mice increases the size of NMJ without substantial changes in muscle fiber size suggesting that preservation of specific force in aged animals overexpressing IGF-1 in muscle is achieved, in part, by improved motor neurons-muscle coupling (Payne et al., 2006).

\section{AGRIN-MUSK SIGNALING PATHWAY}

Acetylcholine receptors clustering on the post-synaptic membrane is a main event in the differentiation of NMJ. This process requires the presence of neural agrin, a basal lamina proteoglycan that activates a muscle-specific kinase (MuSK), which is essential for AChR clustering.

Agrin is transported along the axons and finally released into synaptic basal lamina where it is inactivated by cleavage from neurotrypsin, a synaptic protease, which produces a soluble $22 \mathrm{kDa}$ C-terminal agrin fragment (CAF). Importantly, CAF can be easily detected and measured in human serum (Bolliger et al., 2010; Butikofer et al., 2011). The destabilization of the NMJ by proteolysis of agrin results in precocious sarcopenia (Drey et al., 
2013; Hettwer et al., 2013). This is consistent with findings in experiments with transgenic mice overexpressing neurotrypsin in spinal motoneurons that shown the full sarcopenia phenotype (Butikofer et al., 2011).

\section{Wnt SIGNALING PATHWAY}

There is wide evidence, both in animals models and in humans, the Wnt signaling pathway is down regulated with aging and contributes to the progressive reduction in muscle regeneration and repair capacity (Conboy and Rando, 2012). Wnt proteins are a large family (19 members in humans) of secreted glycoproteins that are highly evolutionary conserved. Wnt signaling modulates the formation and the function of synapses and is involved in maintenance and function of many tissues including muscle and nerve. Wnt deregulation produces many neurodegenerative and mental diseases (Okerlund and Cheyette, 2011; Mulligan and Cheyette, 2012; Stamatakou and Salinas, 2013).

The role of WNT signaling on the NMJ is complex. Canonical and non-canonical Wnt pathways exert opposite effects on the formation of the vertebrate NMJ (Korkut and Budnik, 2009). The non-canonical Wnt cascade has a positive role on post-synaptic development. In contrast, activation of the canonical Wnt pathway has a negative effect on NMJ formation. Thus, while the role of Wnt signaling on NMJ development and in muscle regeneration impairment with aging is well established, evidence for a direct effect of Wnt on NMJ plasticity, maintenance, and repair is lacking and requires further investigation.

\section{VOLTAGE-GATED SODIUM CHANNEL: $\mathrm{Na}_{\mathrm{v}} \mathbf{1 . 5}$}

The $\mathrm{Na}_{\mathrm{V}}$ channel gene family $\left(\mathrm{Na}_{\mathrm{V}} 1.1-\mathrm{Na}_{\mathrm{V}} 1.9, \mathrm{NaVX}\right)$ codes for voltage-gated sodium channels ( $\mathrm{NaChs}$ ), which are essential for the initiation and propagation of action potentials in both nerve and muscle (Young and Caldwell, 2005). Adult skeletal muscle expresses two isoforms of Nav (Nav1.4 and Nav1.5) (Rannou et al., 2011; Kraner et al., 2012). The isoform $\mathrm{Na}_{\mathrm{v}} 1.5$ is particularly relevant to aging because it is mainly expressed in adult muscle following denervation (Kallen et al., 1990; Morel et al., 2010). Consistently, fibers positive for tetrodotoxin resistant (TTX-R) $\mathrm{Na}_{\mathrm{v}} 1.5$ channels are more prevalent in muscles from old compared with young mice, suggesting a potential biomarker for muscle denervation during aging (Wang et al., 2005; Rowan et al., 2012).

\section{PEROXISOME PROLIFERATOR-ACTIVATED RECEPTOR GAMMA COACTIVATOR 1-ALPHA (PGC-1 $\alpha$ )}

Peroxisome proliferator-activated receptor gamma coactivator 1alpha $(\mathrm{PGC}-1 \alpha)$ is a transcription factor that promotes mitochondrial biogenesis. Studies have consistently shown that PGC$1 \alpha$ decline with aging and in many age-related chronic diseases suggesting that such decline may explain the progressive mitochondrial dysfunction with aging.

Recent studies using muscle-specific PGC-1 $\alpha$ knockout and PGC- $1 \alpha$ overexpressing mice have suggested that PGC- $1 \alpha$ is a key protein involved in NMJ integrity, and the decline in PGC-1 $\alpha$ may cause NMJ degeneration with aging by a mechanism that is separate from the effect of PGC-1 $\alpha$ on mitochondrial biogenesis (Handschin et al., 2007; Wenz et al., 2009; Liang et al., 2011; Gouspillou et al., 2013). There is recent strong evidence that elevated activity of the co-activator PGC-1 $\alpha$ in skeletal muscle contributes to the efficient pre- and post-synaptic remodeling of the NMJ (Arnold et al., 2014).

Gouspillou et al. (2013) hypothesized that the denervation and innervation cycle observed with aging is under the control of PGC- $1 \alpha$ expression and proposed that the aging-related decline in PGC- $1 \alpha$ may be a central mechanism promoting instability of the NMJ and consequently aging-related alterations of myofiber innervation in sarcopenia. Interestingly, the decline in muscle PGC- $1 \alpha$ levels with aging is attenuated by caloric restriction (CR) and exercise (Derbre et al., 2012; Garcia-Valles et al., 2013).

\section{PROTEIN DEGRADATION PATHWAYS: MAFbx AND MuRF1}

The ubiquitin-proteasome and the autophagic-lysosomal pathways are activated during disease-related muscle atrophy and, perhaps, during the development of age-related sarcopenia. The ubiquitin-proteasome system is required to remove sarcomeric proteins, either because they are damaged or in response to decline in muscle activity. Two main enzymes at the core of this system, the ubiquitin ligases muscle atrophy f-box (Atrogin1/MAFbx) and muscle ring finger-1 (MuRF1), increase significantly in muscular atrophy, in part due to enhanced expression of tumor necrosis factor alpha $(\mathrm{TNF}-\alpha)$. Mice lacking both are resistant to atrophy induced by denervation (Bodine et al., 2001; Lecker et al., 2004; Nordquist et al., 2007; Furlow et al., 2013). There is some evidence that MuRF1 could play a role in NMJ control by regulating AChR lifetime, implicating a role of MuRF1 in membrane protein turnover during aging (Rudolf et al., 2013; Franke et al., 2014; Khan et al., 2014).

\section{THE STUDY OF NMJ IN AGING: ANIMALS MODELS}

The NMJ is the best model to study synaptogenesis, because, at least in animals, it is experimentally accessible in a living organism. The mechanisms that lead to differentiation and maturation of the NMJ have been studied extensively while changes that occur with aging and lead to impairment of the NMJ are not fully understood. Most of the studies conducted in this field focused on early development (i.e., the $\mathrm{KO}$ mice for synaptic regulators such as rapsyn, agrin, MuSK, and AChR) (Yampolsky et al., 2010; Witzemann et al., 2013). Mouse models that were originally developed to study neuromuscular diseases [i.e., amyotrophic lateral sclerosis (ALS) ] could be used to explore the effect of aging on the NMJ. The prototype of these models is the Sod $1^{-/-}$mice.

\section{Sod1 $\%$ MICE}

The homozygous deletion of $\mathrm{Cu} / \mathrm{Zn}$ superoxide dismutase $(\mathrm{Cu} / \mathrm{Zn}$ SOD) leads to age-dependent muscle atrophy with alterations in NMJ similar to, but more severe than aging-related muscle atrophy (Sakellariou et al., 2011, 2014). This model is of great interest because the main function of SOD is to scavenge free oxygen radicals, being the oxidative stress, one of the landmarks of aging.

The Sod $1^{-/}$mice were originally created to study ALS and addresses pathological events in the spinal cord, peripheral axons, and muscle. However, the neuromuscular sarcopenic phenotypes exhibited by this mouse share several characteristics with age-related sarcopenia, namely shift from fast to slow fiber type, mitochondrial dysfunction, and increased mitochondrial ROS 
generation (Jang and Van Remmen, 2009, 2011). In particular, the mitochondrial dysfunction might contribute to early motor terminal death in these mice (Muller et al., 2007). Rocha et al. (2013) have shown that the Sod1 ${ }^{-/-}$mice undergo cycles of denervation/re-innervation by mixed NMJ populations (Sod1a, Sod1b) supporting morphological evidence for two populations of motor units in Sod $1^{-/}$mice (Schaefer et al., 2005). All together these data suggest that the impairment in neuromuscular transmission follows post-synaptic changes.

\section{MRF4-NULL MICE}

Muscle regulatory factor 4 (MRF4) is a member of the family of myogenic transcription factors (MyoD, myogenin, and myf-5) necessary for the differentiation of skeletal muscle (Weis et al., 2000). MRF4-null mice express genes encoding nAChR subunits and contractile proteins at normal levels, but express myogenin at dramatically increased levels. These mice have normal morphology and fiber-type composition (Zhang et al., 1995) and reduced expression of the $\mathrm{Na}_{\mathrm{v}}$ 1.4 $\mathrm{NaCh}$ (Snow et al., 2005). Denervation leads to a rapid increase of MRF4 protein in myofiber and satellite cell nuclei in all muscle fiber types, suggesting that MRF4 might mediates the earliest responses to denervation and muscle damage (Weis et al., 2000). The NMJs in these mice at older age show higher levels of synaptic vesicle glycoprotein 2B (SV2B) a marker of synaptic vesicles and a decrease in MRF4 expression, suggesting an age-related loss of vesicles in the pre-synaptic terminal of MRF4-null mice that could lead to NMJ dysfunction (Wang et al., 2011). These authors propose MRF4 as a good therapeutic target to restoring and maintaining $\mathrm{NMJ}$ in aging and diseases.

\section{INTERVENTIONS TO IMPROVE NMJ DYSFUNCTION IN AGING}

Caloric restriction and exercise attenuate age-related declines in most physiological systems including the neuromuscular system (McKiernan et al., 2004; Gillette-Guyonnet and Vellas, 2008; Valdez et al., 2010; Mercken et al., 2012; Chistiakov et al., 2014). It has been shown that CR, but not exercise, blunts age-related loss of motor neurons and muscle fibers (Deschenes, 2011). Aging 'per se' limits the capacity of a person to adapt to an exercise training program since muscle plasticity is reduced with aging (Degens, 2010). Because the NMJ could be impaired during aging, with a reduced capacity to adapt to fatigue, CR and exercise are candidate interventions to delay the onset of age-related NMJ dysfunction and sarcopenia.

\section{CALORIC RESTRICTION}

Caloric restriction has long been shown to be the most effective, non-genetic intervention to extend lifespan and delay the onset of age-related diseases (McCay et al., 1935; Fontana et al., 2010; Anderson and Weindruch, 2012; Gouspillou and Hepple, 2013). Valdez et al. (2010) found that CR from 4 to 24 months of age led to sparing of many NMJs in the tibialis anterior (TA) muscle in mice. The frequencies of fragmented and denervated post-synaptic sites were all significantly lower in these calorically restricted mice than in controls. The authors concluded that CR reduced the incidence of axonal atrophy and attenuated the deleterious effects of age on the structure of the NMJ. Other authors have found that dietary restriction (40\% of ad libitum fed diet) attenuates age-associated muscle atrophy by lowering oxidative stress in Sod $1^{-/-}$mice and up-regulating manganese superoxide dismutase (MnSOD), the main mitochondrial antioxidant enzyme responsible for scavenging superoxide produced by the mitochondrial electron transport chain (ETC). These data suggest that the CR model may be useful to identify mechanisms and targets for interventions aimed at preservation of NMJ with aging (Jang et al., 2012). Furthermore, Mayhew et al. (1998) propose that CR preserves the mechanical properties of aging skeletal muscles in rats through an increased expression of DHPRs.

\section{EXERCISE}

Voluntary physical activity declines with aging in humans and in most other animal species. The consequent reduction in fitness leads to reduced resistance to fatigue, lower muscle strength, and increased risk of frailty (Degens and Alway, 2006; Ferrucci et al., 2008; Afilalo et al., 2014). Neuromuscular fatigue (progressively impaired transduction of action potentials through the NMJ during exercise) has been identified as a factor constraining exercise intensity and duration, and a contributor to reduced response to exercise training during aging (Belluardo et al., 2001; Deschenes, 2011). A recent review highlighted the beneficial effects of exercise on the maintenance and regeneration of NMJs (Nishimune et al., 2014). Exercise induces NMJ hypertrophy and improves recovery from peripheral nerve injuries, while decreased physical activity results in NMJ degeneration and nerve terminal sprouting (Wilson and Deschenes, 2005; Nishimune et al., 2012, 2014). Clark et al. (2013) suggest that voluntary neuromuscular activation declines with advancing age, contributing to a reduction in power production, and precedes the decline of mobility function. Aging limit the capacity of NMJ to adapt to endurance training (Deschenes et al., 2010; Valdez et al., 2010). These findings suggest that in the presence of mitochondrial DNA (mtDNA) mutation induced by ROS, strength training (ST) can reverse the loss of muscle function and altered muscle morphology associated with age and can promote the normalization of dysfunctional mitochondria (Hurley et al., 2011). Voluntary running exercise begun in late middle-age is sufficient to preserve much of the endplate nerve terminal area (Cheng et al., 2013). In mice, endurance training reduced muscle fiber size in young adults even as NMJ size increased (Deschenes, 2011). Also, in mice, Fahim (1997) showed that if the exercise training is introduced during old age, the age-related expansion of NMJ is minimized and modulated at a lower level compared with sedentary controls, indicating that the mouse NMJ undergoes a process of physiological and morphological remodeling during aging, and such plasticity could be modulated differently by endurance exercise.

\section{CONCLUSION AND FUTURE DIRECTIONS}

Age-related NMJ dysfunction seems to be a key to understanding musculoskeletal impairment during aging. Morphological changes together with physiological alterations result in a remodeling of the motor unit and in a decline of the number of motor neurons, particularly the type II muscle fiber. These changes lead to excitation-contraction uncoupling, and a loss of communication between the nervous and muscular system, causing a decline 
in skeletal muscle strength and muscle mass. Despite the extensive evidence about muscle denervation in older persons, because the direct study of NMJ in humans remains extremely challenging, it remains unclear whether denervation precedes sarcopenia or vice versa. Understanding the molecular basis of NMJ dysfunction is essential and the study of biomarker is essential both to make scientific progress in this area and translating such research in search for new treatment. Not only new structural and molecular studies, but also novel animal models to clarify what really happens to this key connection between brain and muscle are needed.

\section{ACKNOWLEDGMENTS}

This review was supported entirely by the Intramural Research Program of the NIH, National Institute on Aging.

\section{REFERENCES}

Afilalo, J., Alexander, K. P., Mack, M. J., Maurer, M. S., Green, P., Allen, L. A., et al. (2014). Frailty assessment in the cardiovascular care of older adults. J. Am. Coll. Cardiol. 63, 747-762. doi:10.1016/j.jacc.2013.09.070

Andersen, J. L. (2003). Muscle fibre type adaptation in the elderly human muscle. Scand. J. Med. Sci. Sports 13, 40-47. doi:10.1034/j.1600-0838.2003.00299.x

Anderson, R. M., and Weindruch, R. (2012). The caloric restriction paradigm: implications for healthy human aging. Am. J. Hum. Biol. 24, 101-106. doi:10.1002/ ajhb. 22243

Apel, P. J., Ma, J., Callahan, M., Northam, C. N., Alton, T. B., Sonntag, W. E., et al. (2010). Effect of locally delivered IGF-1 on nerve regeneration during aging: an experimental study in rats. Muscle Nerve 41, 335-341. doi:10.1002/ mus. 21485

Arnold, A. S., Gill, J., Christe, M., Ruiz, R., McGuirk, S., St-Pierre, J., et al. (2014). Morphological and functional remodelling of the neuromuscular junction by skeletal muscle PGC-1alpha. Nat Commun 5, 3569. doi:10.1038/ncomms4569

Arrowsmith, J. E. (2007). The neuromuscular junction. Surgery (Oxford) 25, 105-111. doi:10.1016/j.mpsur.2007.02.001

Baines, H. L., Turnbull, D. M., and Greaves, L. C. (2014). Human stem cell aging: do mitochondrial DNA mutations have a causal role? Aging Cell 13, 201-205. doi:10.1111/acel.12199

Banker, B. Q., Kelly, S. S., and Robbins, N. (1983). Neuromuscular transmission and correlative morphology in young and old mice. J. Physiol. 339, 355-377.

Barrett, E. F., Barrett, J. N., and David, G. (2011). Mitochondria in motor nerve terminals: function in health and in mutant superoxide dismutase 1 mouse models of familial ALS. J. Bioenerg. Biomembr. 43, 581-586. doi:10.1007/s10863-0119392-1

Belluardo, N., Westerblad, H., Mudo, G., Casabona, A., Bruton, J., Caniglia, G., et al. (2001). Neuromuscular junction disassembly and muscle fatigue in mice lacking neurotrophin 4. Mol. Cell. Neurosci. 18, 56-67. doi:10.1006/mcne.2001.1001

Bodine, S. C., Latres, E., Baumhueter, S., Lai, V. K., Nunez, L., Clarke, B. A., et al. (2001). Identification of ubiquitin ligases required for skeletal muscle atrophy. Science 294, 1704-1708. doi:10.1126/science.1065874

Bolliger, M. F., Zurlinden, A., Luscher, D., Butikofer, L., Shakhova, O., Francolini, M., et al. (2010). Specific proteolytic cleavage of agrin regulates maturation of the neuromuscular junction. J. Cell Sci. 123(Pt 22), 3944-3955. doi: $10.1242 /$ jcs.072090

Butikofer, L., Zurlinden, A., Bolliger, M. F., Kunz, B., and Sonderegger, P. (2011). Destabilization of the neuromuscular junction by proteolytic cleavage of agrin results in precocious sarcopenia. FASEB J. 25, 4378-4393. doi:10.1096/fj.11191262

Chai, R. J., Vukovic, J., Dunlop, S., Grounds, M. D., and Shavlakadze, T. (2011). Striking denervation of neuromuscular junctions without lumbar motoneuron loss in geriatric mouse muscle. PLoS ONE 6:e28090. doi:10.1371/journal.pone. 0028090

Cheng, A., Morsch, M., Murata, Y., Ghazanfari, N., Reddel, S. W., and Phillips, W. D. (2013). Sequence of age-associated changes to the mouse neuromuscular junction and the protective effects of voluntary exercise. PLoS ONE 8:e67970. doi:10.1371/journal.pone.0067970
Chistiakov, D. A., Sobenin, I. A., Revin, V. V., Orekhov, A. N., and Bobryshev, Y. V. (2014). Mitochondrial Aging and Age-Related Dysfunction of Mitochondria. BioMed. Res. Int. 2014, 238463. doi:10.1155/2014/238463

Clark, D. J., and Fielding, R. A. (2012). Neuromuscular contributions to age-related weakness. J Gerontol A. Biol. Sci. Med. Sci. 67, 41-47. doi:10.1093/ gerona/glr041

Clark, D. J., Pojednic, R. M., Reid, K. F., Patten, C., Pasha, E. P., Phillips, E. M., et al. (2013). Longitudinal decline of neuromuscular activation and power in healthy older adults. J. Gerontol. 68, 1419-1425. doi:10.1093/gerona/glt036

Conboy, I. M., and Rando, T. A. (2012). Heterochronic parabiosis for the study of the effects of aging on stem cells and their niches. Cell Cycle (Georgetown, Tex.) 11, 2260-2267. doi:10.4161/cc.20437

Degens, H. (2010). The role of systemic inflammation in age-related muscle weakness and wasting. Scand. J. Med. Sci. Sports 20, 28-38. doi:10.1111/j.1600-0838. 2009.01018.x

Degens, H., and Alway, S. E. (2006). Control of muscle size during disuse, disease, and aging. Int. J. Sports Med. 27, 94-99. doi:10.1055/s-2005-837571

Delbono, O. (2000). Regulation of excitation contraction coupling by insulin-like growth factor-1 in aging skeletal muscle. J. Nutr. Health Aging 4, 162-164.

Delbono, O. (2003). Neural control of aging skeletal muscle. Aging Cell 2, 21-29. doi:10.1046/j.1474-9728.2003.00011.x

Delbono, O., O’Rourke, K. S., and Ettinger, W. H. (1995). Excitation-calcium release uncoupling in aged single human skeletal muscle fibers. J. Memb. Biol. 148, 211-222. doi:10.1007/BF00235039

Delbono, O., Renganathan, M., and Messi, M. L. (1997). Excitation-Ca2+ releasecontraction coupling in single aged human skeletal muscle fiber. Muscle Nerve Suppl. 5, S88-S92. doi:10.1002/(SICI)1097-4598(1997)5+<88::AID-MUS21>3. $0 . \mathrm{CO} ; 2-\mathrm{U}$

Derbre, F., Gomez-Cabrera, M. C., Nascimento, A. L., Sanchis-Gomar, F., MartinezBello, V. E., Tresguerres, J. A., et al. (2012). Age associated low mitochondrial biogenesis may be explained by lack of response of PGC-1alpha to exercise training. Age (Dordr) 34, 669-679. doi:10.1007/s11357-011-9264-y

Deschenes, M. R. (2011). Motor unit and neuromuscular junction remodeling with aging. Curr Aging Sci 4, 209-220. doi:10.2174/1874609811104030209

Deschenes, M. R., Roby, M. A., Eason, M. K., and Harris, M. B. (2010). Remodeling of the neuromuscular junction precedes sarcopenia related alterations in myofibers. Exp. Gerontol. 45, 389-393. doi:10.1016/j.exger.2010.03.007

Drey, M., Sieber, C. C., Bauer, J. M., Uter, W., Dahinden, P., Fariello, R. G., et al. (2013). C-terminal agrin fragment as a potential marker for sarcopenia caused by degeneration of the neuromuscular junction. Exp. Gerontol. 48, 76-80. doi:10.1016/j.exger.2012.05.021

Dupuis, L., Gonzalez de Aguilar, J.-L., Echaniz-Laguna, A., Eschbach, J., Rene, F., Oudart, H., et al. (2009). Muscle mitochondrial uncoupling dismantles neuromuscular junction and triggers distal degeneration of motor neurons. PLoS ONE 4:e5390. doi:10.1371/journal.pone.0005390

Dupuis, L., Oudart, H., Rene, F., Gonzalez de Aguilar, J. L., and Loeffler, J. P. (2004). Evidence for defective energy homeostasis in amyotrophic lateral sclerosis: benefit of a high-energy diet in a transgenic mouse model. Proc. Natl. Acad. Sci. US A. 101, 11159-11164. doi:10.1073/pnas.0402026101

Dupuis, L., Pradat, P. F., Ludolph, A. C., and Loeffler, J. P. (2011). Energy metabolism in amyotrophic lateral sclerosis. Lancet Neurol. 10, 75-82. doi:10.1016/ S1474-4422(10)70224-6

Fahim, M. A. (1997). Endurance exercise modulates neuromuscular junction of C57BL/6NNia aging mice. J. Appl. Physiol. 83, 59-66.

Ferrucci, L., Baroni, M., Ranchelli, A., Lauretani, F., Maggio, M., Mecocci, P., et al. (2014). Interaction between bone and muscle in older persons with mobility limitations. Curr. Pharm. Des. 20, 3178-3197. doi:10.2174/13816128113196660690

Ferrucci, L., Corsi, A., Lauretani, F., Bandinelli, S., Bartali, B., Taub, D. D., et al. (2005). The origins of age-related proinflammatory state. Blood 105, 2294-2299. doi:10.1182/blood-2004-07-2599

Ferrucci, L., de Cabo, R., Knuth, N. D., and Studenski, S. (2012). Of Greek heroes, wiggling worms, mighty mice, and old body builders. J Gerontol. A. Biol. Sci. Med. Sci. 67, 13-16. doi:10.1093/gerona/glr046

Ferrucci, L., Giallauria, F., and Schlessinger, D. (2008). Mapping the road to resilience: novel math for the study of frailty. Mech. Ageing Dev. 129, 677-679. doi:10.1016/j.mad.2008.09.007

Ferrucci, L., Harris, T. B., Guralnik, J. M., Tracy, R. P., Corti, M. C., Cohen, H. J., et al. (1999). Serum IL-6 level and the development of disability in older persons. $J$. Am. Geriatr. Soc. 47, 639-646. 
Fontana, L., Partridge, L., and Longo, V. D. (2010). Extending healthy life span - from yeast to humans. Science 328, 321-326. doi:10.1126/science.1172539

Franceschi, C., Capri, M., Monti, D., Giunta, S., Olivieri, F., Sevini, F., et al. (2007). Inflammaging and anti-inflammaging: a systemic perspective on aging and longevity emerged from studies in humans. Mech Ageing Dev 128, 92-105. doi:10.1016/j.mad.2006.11.016

Franke, B., Gasch, A., Rodriguez, D., Chami, M., Khan, M. M., Rudolf, R., et al. (2014). Molecular basis for the fold organization and sarcomeric targeting of the muscle atrogin MuRF1. Open Biol. 4, 130172. doi:10.1098/rsob.130172

Furlow, J. D., Watson, M. L., Waddell, D. S., Neff, E. S., Baehr, L. M., Ross, A. P., et al. (2013). Altered gene expression patterns in muscle ring finger 1 null mice during denervation- and dexamethasone-induced muscle atrophy. Physiol. Genomics 45, 1168-1185. doi:10.1152/physiolgenomics.00022.2013

Garcia, M. L., Fernandez, A., and Solas, M. T. (2013). Mitochondria, motor neurons and aging. J. Neurol. Sci.330, 18-26. doi:10.1016/j.jns.2013.03.019

Garcia-Valles, R., Gomez-Cabrera, M. C., Rodriguez-Manas, L., Garcia-Garcia, F. J., Diaz, A., Noguera, I., et al. (2013). Life-long spontaneous exercise does not prolong lifespan but improves health span in mice. Longev. Healthspan 2, 14. doi:10.1186/2046-2395-2-14

Gillette-Guyonnet, S., and Vellas, B. (2008). Caloric restriction and brain function. Curr. Opin. Clin. Nutr. Metab. Care 11, 686-692. doi:10.1097/MCO. 0b013e328313968f

Glass, D., and Roubenoff, R. (2010). Recent advances in the biology and therapy of muscle wasting. Ann. N Y Acad. Sci. 1211, 25-36. doi:10.1111/j.1749-6632.2010. 05809.x

Gomez-Pinilla, F. (2011). The combined effects of exercise and foods in preventing neurological and cognitive disorders. Prev. Med. 52(Suppl. 1), S75-S80. doi:10.1016/j.ypmed.2011.01.023

Gomez-Pinilla, F., Ying, Z., Roy, R. R., Molteni, R., and Edgerton, V. R. (2002). Voluntary exercise induces a BDNF-mediated mechanism that promotes neuroplasticity. J. Neurophysiol. 88, 2187-2195. doi:10.1152/jn.00152.2002

Gordon, T., Udina, E., Verge, V. M. K., and de Chaves, E. I. P. (2009). Brief electrical stimulation accelerates axon regeneration in the peripheral nervous system and promotes sensory axon regeneration in the central nervous system. Motor Control 13, 412-441.

Gouspillou, G., and Hepple, R. T. (2013). Facts and controversies in our understanding of how caloric restriction impacts the mitochondrion. Exp. Gerontol. 48, 1075-1084. doi:10.1016/j.exger.2013.03.004

Gouspillou, G., Picard, M., Godin, R., Burelle, Y., and Hepple, R. T. (2013). Role of peroxisome proliferator-activated receptor gamma coactivator 1-alpha (PGClalpha) in denervation-induced atrophy in aged muscle: facts and hypotheses. Longev. Healthspan 2, 13. doi:10.1186/2046-2395-2-13

Gyorkos, A. M., McCullough, M. J., and Spitsbergen, J. M. (2014). Glial cell linederived neurotrophic factor (GDNF) expression and NMJ plasticity in skeletal muscle following endurance exercise. Neuroscience 257, 111-118. doi:10.1016/j. neuroscience.2013.10.068

Handschin, C., Kobayashi, Y. M., Chin, S., Seale, P., Campbell, K. P., and Spiegelman, B. M. (2007). PGC-1alpha regulates the neuromuscular junction program and ameliorates Duchenne muscular dystrophy. Genes Dev. 21, 770-783. doi:10.1101/gad.1525107

Hettwer, S., Dahinden, P., Kucsera, S., Farina, C., Ahmed, S., Fariello, R. et al. (2013). Elevated levels of a C-terminal agrin fragment identifies a new subset of sarcopenia patients. Exp. Gerontol. 48, 69-75. doi:10.1016/j.exger.2012. 03.002

Huang, E. J., and Reichardt, L. F. (2001). Neurotrophins: roles in neuronal development and function. Ann. Rev. Neurosci. 24, 677-736. doi:10.1146/annurev.neuro. 24.1.677

Hurley, B. F., Hanson, E. D., and Sheaff, A. K. (2011). Strength training as a countermeasure to aging muscle and chronic disease. Sports Med. 41, 289-306. doi:10.2165/11585920-000000000-00000

Ibebunjo, C., Chick, J. M., Kendall, T., Eash, J. K., Li, C., Zhang, Y., et al. (2013). Genomic and proteomic profiling reveals reduced mitochondrial function and disruption of the neuromuscular junction driving rat sarcopenia. Mol. Cel. Biol. 33, 194-212. doi:10.1128/MCB.01036-12

Jang, Y. C., Liu, Y., Hayworth, C. R., Bhattacharya, A., Lustgarten, M. S., Muller, F. L., et al. (2012). Dietary restriction attenuates age-associated muscle atrophy by lowering oxidative stress in mice even in complete absence of CuZnSOD. Aging Cell 11, 770-782. doi:10.1111/j.1474-9726.2012.00843.x
Jang, Y. C., and Van Remmen, H. (2009). The mitochondrial theory of aging: insight from transgenic and knockout mouse models. Exp. Gerontol. 44, 256-260. doi:10.1016/j.exger.2008.12.006

Jang Y. C., and Van Remmen, H. (2011). Age-associated alterations of the neuromuscular junction. Exp. Gerontol. 46, 193-198. doi:10.1016/j.exger.2010. 08.029

Jiang, X., Tian, F., Du, Y., Copeland, N. G., Jenkins, N. A., Tessarollo, L., et al. (2008). BHLHB2 controls Bdnf promoter 4 activity and neuronal excitability. J. Neurosci. 28, 1118-1130. doi:10.1523/JNEUROSCI.2262-07.2008

Kallen, R. G., Sheng, Z. H., Yang, J., Chen, L. Q., Rogart, R. B., and Barchi, R. L. (1990). Primary structure and expression of a sodium channel characteristic of denervated and immature rat skeletal muscle. Neuron 4, 233-242. doi:10.1016/0896-6273(90)90098-Z

Kawabuchi, M., Tan, H., and Wang, S. (2011). Age affects reciprocal cellular interactions in neuromuscular synapses following peripheral nerve injury. Ageing Res. Rev. 10, 43-53. doi:10.1016/j.arr.2010.10.003

Kawabuchi, M., Zhou, C. J., Wang, S., Nakamura, K., Liu, W. T., and Hirata, K. (2001). The spatio temporal relationship among Schwann cells, axons and post-synaptic acetylcholine receptor regions during muscle reinnervation in aged rats. Anat. Rec. 264, 183-202. doi:10.1002/ar.1159

Khan, M. M., Strack, S., Wild, F., Hanashima, A., Gasch, A., Brohm, K., et al. (2014). Role of autophagy, SQSTM1, SH3GLB1, and TRIM63 in the turnover of nicotinic acetylcholine receptors. Autophagy 10, 123-136. doi:10.4161/auto.26841

Kim, H. A., Mindos, T., and Parkinson, D. B. (2013). Plastic fantastic: Schwann cells and repair of the peripheral nervous system. Stem Cells Transl. Med. 2, 553-557. doi:10.5966/sctm.2013-0011

Korkut, C., and Budnik, V. (2009). WNTs tune up the neuromuscular junction. Nat. Rev. Neurosci. 10, 627-634. doi:10.1038/nrn2681

Kraner, S. D., Novak, K. R., Wang, Q., Peng, J., and Rich, M. M. (2012). Altered sodium channel-protein associations in critical illness myopathy. Skelet. Muscle 2, 17. doi:10.1186/2044-5040-2-17

Kurokawa, K., Mimori, Y., Tanaka, E., Kohriyama, T., and Nakamura, S. (1999). Agerelated change in peripheral nerve conduction: compound muscle action potential duration and dispersion. Gerontology 45, 168-173. doi:10.1159/000022081

Lecker, S. H., Jagoe, R. T., Gilbert, A., Gomes, M., Baracos, V., Bailey, J., et al. (2004). Multiple types of skeletal muscle atrophy involve a common program of changes in gene expression. FASEB J. 18, 39-51.

Lexell, J. (1995). Human aging, muscle mass, and fiber type composition. J Gerontol. A. Biol. Sci. Med. Sci. 50 Spec No, 11-16.

Lexell, J. (1997). Evidence for nervous system degeneration with advancing age. J. Nutr. 127, 1011S-1013S.

Li, H., Kumar Sharma, L., Li, Y., Hu, P., Idowu, A., Liu, D., et al. (2013). Comparative bioenergetic study of neuronal and muscle mitochondria during aging. Free Rad. Biol. Med. 63, 30-40. doi:10.1016/j.freeradbiomed.2013.04.030

Li, L., Wu, W., Lin, L. F., Lei, M., Oppenheim, R. W., and Houenou, L. J. (1995). Rescue of adult mouse motoneurons from injury-induced cell death by glial cell line-derived neurotrophic factor. Proc. Natl. Acad. Sci.U S A 92, 9771-9775. doi:10.1073/pnas.92.21.9771

Li, Y., Lee, Y. I., and Thompson, W. J. (2011). Changes in aging mouse neuromuscular junctions are explained by degeneration and regeneration of muscle fiber segments at the synapse. J. Neurosci. 31, 14910-14919. doi:10.1523/JNEUROSCI. 3590-11.2011

Liang, H., Ward, W. F., Jang, Y. C., Bhattacharya, A., Bokov, A. F., Li, Y., et al. (2011). PGC-1alpha protects neurons and alters disease progression in an amyotrophic lateral sclerosis mouse model. Muscle Nerve 44, 947-956. doi:10.1002/mus.22217

Lie, D. C., and Weis, J. (1998). GDNF expression is increased in denervated human skeletal muscle. Neurosci. Lett. 250, 87-90. doi:10.1016/S0304-3940(98)00434-0

Lin, L. F., Doherty, D. H., Lile, J. D., Bektesh, S., and Collins, F. (1993). GDNF: a glial cell line-derived neurotrophic factor for midbrain dopaminergic neurons. Science 260, 1130-1132. doi:10.1126/science.8493557

Lin, M. T., and Beal, M. F. (2006). Mitochondrial dysfunction and oxidative stress in neurodegenerative diseases. Nature 443, 787-795. doi:10.1038/nature05292

Lipsky, R. H., and Marini, A. M. (2007). Brain-derived neurotrophic factor in neuronal survival and behavior-related plasticity. Ann. NY Acad. Sci 1122, 130-143. doi:10.1196/annals.1403.009

Luff, A. R. (1998). Age-associated changes in the innervation of muscle fibers and changes in the mechanical properties of motor units. Ann. N. Y. Acad. Sci. 854, 92-101. doi:10.1111/j.1749-6632.1998.tb09895.x 
Maggio, M., Ble, A., Ceda, G. P., and Metter, E. J. (2006). Decline in insulin-like growth factor-I levels across adult life span in two large population studies. $J$. Gerontol. A Biol. Sci. Med. Sci. 61, 182-183. doi:10.1093/gerona/61.2.182

Maggio, M., De Vita, F., Lauretani, F., Butto, V., Bondi, G., Cattabiani, C., et al. (2013). IGF-1, the cross road of the nutritional, inflammatory and hormonal pathways to frailty. Nutrients 5, 4184-4205. doi:10.3390/nu5104184

Manini, T. M., Hong, S. L., and Clark, B. C. (2013). Aging and muscle: a neuron's perspective. Curr. Opin. Clin. Nutr. Metab. Care 16, 21-26. doi:10.1097/MCO. 0b013e32835b5880

Mayhew, M., Renganathan, M., and Delbono, O. (1998). Effectiveness of caloric restriction in preventing age-related changes in rat skeletal muscle. Biochem. Biophys. Res. Commun. 251, 95-99. doi:10.1006/bbrc.1998.9438

McCay, C. M., Crowell, M. F., and Maynard, L. A. (1935). The effect of retarded growth upon the length of life span and upon the ulti- mate body size. J. Nutr. $10,63-79$.

McCullough, M. J., Gyorkos, A. M., and Spitsbergen, J. M. (2013). Short-term exercise increases GDNF protein levels in the spinal cord of young and old rats. Neuroscience 240, 258-268. doi:10.1016/j.neuroscience.2013.02.063

McCullough, M. J., Peplinski, N. G., Kinnell, K. R., and Spitsbergen, J. M. (2011). Glial cell line-derived neurotrophic factor protein content in rat skeletal muscle is altered by increased physical activity in vivo and in vitro. Neuroscience 174, 234-244. doi:10.1016/j.neuroscience.2010.11.016

McKiernan, S. H., Bua, E., McGorray, J., and Aiken, J. (2004). Early-onset calorie restriction conserves fiber number in aging rat skeletal muscle. FASEB J. 18, 580-581.

Mercken, E. M., Carboneau, B. A., Krzysik-Walker, S. M., and de Cabo, R. (2012). Of mice and men: the benefits of caloric restriction, exercise, and mimetics. Ageing Res. Rev. 11, 390-398. doi:10.1016/j.arr.2011.11.005

Messi, M. L., and Delbono, O. (2003). Target-derived trophic effect on skeletal muscle innervation in senescent mice. J. Neurosci. 23, 1351-1359.

Morel, J., Rannou, F., Talarmin, H., Giroux-Metges, M. A., Pennec, J. P., Dorange, G., et al. (2010). Sodium channel $\mathrm{Na}(\mathrm{V}) 1.5$ expression is enhanced in cultured adult rat skeletal muscle fibers. J. Membr. Biol. 235, 109-119. doi:10.1007/s00232-010-9262-5

Muller, F. L., Song, W., Jang, Y. C., Liu, Y., Sabia, M., Richardson, A., et al. (2007). Denervation-induced skeletal muscle atrophy is associated with increased mitochondrial ROS production. Am. J. Physiol. Regul. Integr. Comp. Physiol. 293, R1159-R1168. doi:10.1152/ajpregu.00767.2006

Mulligan, K. A., and Cheyette, B. N. R. (2012). Wnt signaling in vertebrate neural development and function. J. Neuroimmune Pharmacol. 7, 774-787. doi:10.1007/s11481-012-9404-x

Musaro, A., McCullagh, K., Paul, A., Houghton, L., Dobrowolny, G., Molinaro, M., et al. (2001). Localized IGF-1 transgene expression sustains hypertrophy and regeneration in senescent skeletal muscle. Nat. Genet. 27, 195-200. doi: $10.1038 / 84839$

Navarro, A., and Boveris, A. (2009). Brain mitochondrial dysfunction and oxidative damage in Parkinson's disease. J. Bioenerg. Biomembr 41, 517-521. doi:10.1007/ s10863-009-9250-6

Nguyen, Q. T., Parsadanian, A. S., Snider, W. D., and Lichtman, J. W. (1998). Hyperinnervation of neuromuscular junctions caused by GDNF overexpression in muscle. Science 279, 1725-1729. doi:10.1126/science.279.5357.1725

Nishimune, H., Numata, T., Chen, J., Aoki, Y., Wang, Y., Starr, M. P., et al. (2012). Active zone protein Bassoon co-localizes with presynaptic calcium channel, modifies channel function, and recovers from aging related loss by exercise. PLoS ONE 7:e38029. doi:10.1371/journal.pone.0038029

Nishimune, H., Stanford, J. A., and Mori, Y. (2014). Role of exercise in maintaining the integrity of the neuromuscular junction. Muscle \& Nerve 49, 315-324. doi:10.1002/mus.24095

Nordquist, J., Hoglund, A. S., Norman, H., Tang, X., Dworkin, B., and Larsson, L. (2007). Transcription factors in muscle atrophy caused by blocked neuromuscular transmission and muscle unloading in rats. Mol. Med. 13, 461-470. doi:10.2119/2006-00066

Okerlund, N. D., and Cheyette, B. N. (2011). Synaptic Wnt signaling; a contributor to major psychiatric disorders? J. Neurodev. Disord. 3, 162-174. doi:10.1007/ s11689-011-9083-6

Payne, A. M., Zheng, Z., Messi, M. L., Milligan, C. E., Gonzalez, E., and Delbono, O. (2006). Motor neurone targeting of IGF-1 prevents specific force decline in ageing mouse muscle. J. Physiol. 570(Pt 2), 283-294. doi:10.1113/jphysiol.2005. 100032
Peng, H. B., Yang, J. F., Dai, Z., Lee, C. W., Hung, H. W., Feng, Z. H., et al. (2003). Differential effects of neurotrophins and Schwann cell-derived signals on neuronal survival/growth and synaptogenesis. J. Neurosci. 23, 5050-5060.

Peterson, C. M., Johannsen, D. L., and Ravussin, E. (2012). Skeletal muscle mitochondria and aging: a review. J. Aging Res. 2012, 194821. doi:10.1155/2012/194821

Punga, A. R., and Ruegg, M. A. (2012). Signaling and aging at the neuromuscular synapse: lessons learnt from neuromuscular diseases. Curr. Opin. Pharmacol. 12, 340-346. doi:10.016/j.coph.2012.02.002

Rangaraju, S., Hankins, D., Madorsky, I., Madorsky, E., Lee, W. H., Carter, C. S., et al. (2009). Molecular architecture of myelinated peripheral nerves is supported by calorie restriction with aging. Aging Cell 8, 178-191. doi:10.1111/j.1474-9726. 2009.00460.x

Rangaraju, S., and Notterpek, L. (2011). Autophagy aids membrane expansion by neuropathic Schwann cells. Autophagy 7, 238-239. doi:10.4161/auto.7.2. 14278

Rannou, F., Pennec, J.-P., Morel, J., Gueret, G., Leschiera, R., Droguet, M., et al. (2011). Na v1.4 and Na v1.5 are modulated differently during muscle immobilization and contractile phenotype conversion. J. Appl. Physiol. 111, 495-507. doi:10.1152/japplphysiol.01136.2010

Reid, K. F., Doros, G., Clark, D. J., Patten, C., Carabello, R. J., Cloutier, G. J., et al. (2012). Muscle power failure in mobility-limited older adults: preserved single fiber function despite lower whole muscle size, quality and rate of neuromuscular activation. Eur J. Appl. Physiol. 112, 2289-2301. doi:10.1007/s00421011-2200-0

Reid, K. F., Pasha, E., Doros, G., Clark, D. J., Patten, C., Phillips, E. M., et al. (2014) Longitudinal decline of lower extremity muscle power in healthy and mobilitylimited older adults: influence of muscle mass, strength, composition, neuromuscular activation and single fiber contractile properties. Eur. J. Appl. Physiol. 114, 29-39. doi:10.1007/s00421-013-2728-2

Rocha, M. C., Pousinha, P. A., Correia, A. M., Sebastiao, A. M., and Ribeiro, J. A. (2013). Early changes of neuromuscular transmission in the SOD1(G93A) mice model of ALS start long before motor symptoms onset. PLoS ONE 8:e73846. doi:10.1371/journal.pone.0073846

Rosenheimer, J. L., and Smith, D. O. (1985). Differential changes in the end-plate architecture of functionally diverse muscles during aging. J. Neurophysiol. 53, 1567-1581.

Rosso, A. L., Studenski, S. A., Chen, W. G., Aizenstein, H. J., Alexander, N. B., Bennett, D. A., et al. (2013). Aging, the central nervous system, and mobility. J Gerontol. A. Biol. Sci. Med. Sci. 68, 1379-1386. doi:10.1093/gerona/glt089

Roubenoff, R. (2000). Sarcopenia and its implications for the elderly. Eur. J. Clin. Nutr. 54(Suppl. 3), S40-S47. doi:10.1038/sj.ejcn.1601024

Rowan, S. L., Rygiel, K., Purves-Smith, F. M., Solbak, N. M., Turnbull, D. M., and Hepple, R. T. (2012). Denervation causes fiber atrophy and myosin heavy chain co-expression in senescent skeletal muscle. PLoS ONE 7:e29082. doi:10.1371/journal.pone.0029082

Rudolf, R., Bogomolovas, J., Strack, S., Choi, K. R., Khan, M. M., Wagner, A., et al. (2013). Regulation of nicotinic acetylcholine receptor turnover by MuRF1 connects muscle activity to endo/lysosomal and atrophy pathways. Age (Dordr) 35, 1663-1674. doi:10.1007/s11357-012-9468-9

Russ, D. W., and Lanza, I. R. (2011). The impact of old age on skeletal muscle energetics: supply and demand. Curr. Aging Sci. 4, 234-247. doi:10.2174/ 1874609811104030234

Saheb-Al-Zamani, M., Yan, Y., Farber, S. J., Hunter, D. A., Newton, P., Wood, M. D., et al. (2013). Limited regeneration in long acellular nerve allografts is associated with increased Schwann cell senescence. Exp. Neurol. 247, 165-177. doi:10.1016/j.expneurol.2013.04.011

Saini, A., Faulkner, S., Al-Shanti, N., and Stewart, C. (2009). Powerful signals for weak muscles. Ageing Res. Rev. 8, 251-267. doi:10.1016/j.arr.2009.02.001

Saini, A., Nasser, A. S., and Stewart, C. E. (2007). Waste management - cytokines, growth factors and cachexia. Cytokine Growth Factor Rev. 17, 475-486. doi:10. 1016/j.cytogfr.2006.09.006

Sakellariou, G. K., Davis, C. S., Shi, Y., Ivannikov, M. V., Zhang, Y., Vasilaki, A., et al. (2014). Neuron-specific expression of CuZnSOD prevents the loss of muscle mass and function that occurs in homozygous CuZnSOD-knockout mice. FASEB J. 28, 1666-1681. doi:10.1096/fj.13-240390

Sakellariou, G. K., Pye, D., Vasilaki, A., Zibrik, L., Palomero, J., Kabayo, T., et al. (2011). Role of superoxide-nitric oxide interactions in the accelerated age-related loss of muscle mass in mice lacking $\mathrm{Cu}, \mathrm{Zn}$ superoxide dismutase. Aging Cell 10, 749-760. doi:10.1111/j.1474-9726.2011.00709.x 
Schaefer, A. M., Sanes, J. R., and Lichtman, J. W. (2005). A compensatory subpopulation of motor neurons in a mouse model of amyotrophic lateral sclerosis. $J$. Comparat. Neurol. 490, 209-219. doi:10.1002/cne.20620

Seeburger, J. L., and Springer, J. E. (1993). Experimental rationale for the therapeutic use of neurotrophins in amyotrophic lateral sclerosis. Exp. Neurol. 124, 64-72. doi:10.1006/exnr.1993.1176

Shear, T. D., and Martyn, J. A. J. (2009). Physiology and biology of neuromuscular transmission in health and disease. J. Crit. Care 24, 5-10. doi:10.1016/j.jcrc.2008. 08.002

Smith, D. O., and Rosenheimer, J. L. (1982). Decreased sprouting and degeneration of nerve terminals of active muscles in aged rats. J. Neurophysiol. 48, 100-109.

Snow, L. M., McLoon, L. K., and Thompson, L. V. (2005). Adult and developmental myosin heavy chain isoforms in soleus muscle of aging Fischer Brown Norway rat. Anat. Rec. A. Discov. Mol. Cell. Evol. Biol. 286, 866-873. doi:10.1002/ar.a.20218

Springer, J. E., Seeburger, J. L., He, J., Gabrea, A., Blankenhorn, E. P., and Bergman, L. W. (1995). cDNA sequence and differential mRNA regulation of two forms of glial cell line-derived neurotrophic factor in Schwann cells and rat skeletal muscle. Exp. Neurol. 131, 47-52. doi:10.1016/0014-4886(95)90006-3

Stamatakou, E., and Salinas, P. C. (2013). Postsynaptic assembly: a role for Wnt signaling. Dev. Neurobiol. doi:10.1002/dneu.22138

Suetta, C., Frandsen, U., Jensen, L., Jensen, M. M., Jespersen, J. G., Hvid, L. G., et al (2012). Aging affects the transcriptional regulation of human skeletal muscle disuse atrophy. PLoS ONE 7:e51238. doi:10.1371/journal.pone.0051238

Tevald, M. A., Foulis, S. A., Lanza, I. R., and Kent-Braun, J. A. (2010). Lower energy cost of skeletal muscle contractions in older humans. Am. J. Physiol. Regul. Integr. Comp. Physiol. 298, R729-R739. doi:10.1152/ajpregu.00713.2009

Valdez, G., Tapia, J. C., Kang, H., Clemenson, G. D., Gage, F. H., Lichtman, J. W., et al. (2010). Attenuation of age-related changes in mouse neuromuscular synapses by caloric restriction and exercise. Proc. Natl. Acad. Sci. U S A 107, 14863-14868. doi:10.1073/pnas.1002220107

Vergani, L., Di Giulio, A. M., Losa, M., Rossoni, G., Muller, E. E., and Gorio, A. (1998). Systemic administration of insulin-like growth factor decreases motor neuron cell death and promotes muscle reinnervation. J. Neurosci. Res. 54, 840-847. doi:10.1002/(SICI) 1097-4547(19981215)54:6<840::AID-JNR12>3.3.CO;2-C

Verge, V. M., Gratto, K. A., Karchewski, L. A., and Richardson, P. M. (1996). Neurotrophins and nerve injury in the adult. Philos. Trans. R. Soc. Lond. B. Biol. Sci. 351, doi:10.1098/rstb.1996.0038

Wang, Q., Hebert, S. L., Rich, M. M., and Kraner, S. D. (2011). Loss of synaptic vesicles from neuromuscular junctions in aged MRF4-null mice. Neuroreport 22, 185-189. doi:10.1097/WNR.0b013e328344493c

Wang, X., Engisch, K. L., Li, Y., Pinter, M. J., Cope, T. C., and Rich, M. M. (2004). Decreased synaptic activity shifts the calcium dependence of release at the mammalian neuromuscular junction in vivo. J. Neurosci. 24, 10687-10692. doi:10.1523/JNEUROSCI.2755-04.2004

Wang, Z. M., Zheng, Z., Messi, M. L., and Delbono, O. (2005). Extension and magnitude of denervation in skeletal muscle from ageing mice. J. Physiol. 565(Pt 3), 757-764. doi:10.1113/jphysiol.2005.087601
Weis, J., Kaussen, M., Calvo, S., and Buonanno, A. (2000). Denervation induces a rapid nuclear accumulation of MRF4 in mature myofibers. Dev. Dyn. 218, 438-451. doi:10.1002/1097-0177(200007)

Wenz, T., Rossi, S. G., Rotundo, R. L., Spiegelman, B. M., and Moraes, C. T. (2009). Increased muscle PGC-1alpha expression protects from sarcopenia and metabolic disease during aging. Proc. Natl. Acad. Sci. U S A. 106, 20405-20410. doi:10.1073/pnas.0911570106

Wilson, M. H., and Deschenes, M. R. (2005). The neuromuscular junction: anatomical features and adaptations to various forms of increased, or decreased neuromuscular activity. Int. J. Neurosci. 115, 803-828. doi:10.1080/ 00207450590882172

Witzemann, V., Chevessier, F., Pacifici, P. G., and Yampolsky, P. (2013). The neuromuscular junction: selective remodeling of synaptic regulators at the nerve/muscle interface. Mech. Dev. 130,402-411. doi:10.1016/j.mod.2012.09.004

Yampolsky, P., Pacifici, P. G., and Witzemann, V. (2010). Differential muscle-driven synaptic remodeling in the neuromuscular junction after denervation. Eur. $J$ Neurosci. 31, 646-658. doi:10.1111/j.1460-9568.2010.07096.x

Young, K. A., and Caldwell, J. H. (2005). Modulation of skeletal and cardiac voltage-gated sodium channels by calmodulin. J. Physiol. 565(Pt 2), 349-370. doi:10.1113/jphysiol.2004.081422

Yuan, Q., Wu, W., So, K. F., Cheung, A. L., Prevette, D. M., and Oppenheim, R. W. (2000). Effects of neurotrophic factors on motoneuron survival following axonal injury in newborn rats. Neuroreport 11, 2237-2241. doi:10.1097/ 00001756-200007140-00035

Zhang, W., Behringer, R. R., and Olson, E. N. (1995). Inactivation of the myogenic bHLH gene MRF4 results in up-regulation of myogenin and rib anomalies. Genes Dev. 9, 1388-1399. doi:10.1101/gad.9.11.1388

Zheng, Z., Wang, Z. M., and Delbono, O. (2002). Insulin-like growth factor-1 increases skeletal muscle dihydropyridine receptor alphals transcriptional activity by acting on the camp-response element-binding protein element of the promoter region. J. Biol. Chem. 277, 50535-50542. doi:10.1074/jbc.M210526200

Conflict of Interest Statement: The authors declare that the research was conducted in the absence of any commercial or financial relationships that could be construed as a potential conflict of interest.

Received: 27 May 2014; accepted: 25 July 2014; published online: 11 August 2014. Citation: Gonzalez-Freire M, de Cabo R, Studenski SA and Ferrucci L (2014) The neuromuscular junction: aging at the crossroad between nerves and muscle. Front. Aging Neurosci. 6:208. doi: 10.3389/fnagi.2014.00208

This article was submitted to the journal Frontiers in Aging Neuroscience.

Copyright (@) 2014 Gonzalez-Freire, de Cabo, Studenski and Ferrucci. This is an openaccess article distributed under the terms of the Creative Commons Attribution License (CC BY). The use, distribution or reproduction in other forums is permitted, provided the original author(s) or licensor are credited and that the original publication in this journal is cited, in accordance with accepted academic practice. No use, distribution or reproduction is permitted which does not comply with these terms. 